L'Exposition est consacrée à l'étude des arts et techniques. On a pensé qu'il serait intéressant de présenter également les productions du travail indigène en faisant venir un certain nombre de sujets français provenant des différentes possessions et qui vendraient au public des broderies, des tapis, des vanneries, des objets sculptés et ornementés en bois, etc. Cette manifestation permettra d'apercevoir l'évolution des pratiques artisanales sous l'influence de la colonisation et d'apprécier les efforts des différents gouvernements locaux pour éviter une dégénérescence des arts indigènes.

\title{
Une Exposition des arts et métiers congolais.
}

Sous les auspices du Ministère des Colonies, une exposition des arts et métiers congolais a été organisée cet hiver à Bruxelles par la Commission pour la Protection des Arts et Métiers Indigènes. Le but de l'exposition étant uniquement de ' montrer par des spécimens choisis les survivances artistiques de notre domaine colonial et ses productions artisanales susceptibles de rénovation dans le cadre de la vie moderne', les caractères esthétiques et l'habileté technique ont exclusivement présidé au choix des objets. Un large apport de collections privées, complété par un emprunt judicieux au Musée de Tervueren, a permis de créer à ce double point de vue un ensemble suggestif.

Des stands furent réservés également aux arts appliqués et décoratifs métropolitains dont les réalisations avaient été guidées par l'esthétique et les techniques congolaises. Par cette initiative l'exposition s'adressait non seulement aux commetçants, industriels et exportateurs soucieux d'adapter leurs marchandises aux goûts de la clientèle indigène, mais aussi aux artistes, ensembliers, décorateurs, artisans d'art européens susceptibles d'y trouver des motifs d'inspiration en vue de renouveler le cas échéant les thèmes de leurs divers travaux.

Désireuse de créer un mouvement d'opinion favorable à l'art congolais, la Commission pour la Protection des Arts et Métiers Indigènes a entrepris la publication d'une série de fascicules intitulés Artes Africanae. (Communication $d u$ PROFESSEUR N. DE CLEENE.) 